\title{
Critical thinking and accuracy of nurses' diagnoses. Part I: risk of low accuracy diagnoses and new views of critical thinking*
}

\author{
PENSAMENTO CRÍTICO E ACURÁCIA DOS DIAGNÓSTICOS DE ENFERMAGEM. PARTE I: RISCO DE \\ DIAGNÓSTICOS DE BAIXAACURÁCIA E NOVAS VISÕES DO PENSAMENTO CRÍTICO
}

PENSAMIENTO CRÍTICO Y PRECISIÓN DE LOS DIAGNÓSTICOS DE ENFERMERÍA. I PARTE: RIESGO DE DIAGNÓSTICOS DE BAJA PRECISIÓN Y NUEVAS PERSPECTIVAS DEL PENSAMIENTO CRÍTICO.

\section{Margaret Lunney ${ }^{1}$}

\section{RESUMO}

A diversidade e complexidade na interpretação dos dados dos pacientes contribuem para o risco de menor acurácia dos diagnósticos de enfermagem. Embora os achados em pesquisa confirmem esse risco pela enorme variação na acurácia, diagnósticos precisos são essenciais para direcionar as intervenções de enfermagem para o alcance de resultados positivos na saúde. $\dot{E}$ provável que o desenvolvimento de habilidades de pensamento crítico melhore a acurácia dos diagnósticos feitos pelas enfermeiras. Novas visões do pensamento crítico servem de base para o pensamento crítico em enfermagem. Sete habilidades cognitivas e dez formas de pensar são identificadas como dimensões do pensamento crítico no uso do processo diagnóstico.

\section{PALAVRAS-CHAVE}

Pensamento crítico. Diagnóstico de enfermagem. Acurácia.

\begin{abstract}
Interpretations of patient data are complex and diverse, contributing to a risk of low accuracy nursing diagnoses. This risk is confirmed in research findings that accuracy of nurses' diagnoses varied widely from high to low. Highly accurate diagnoses are essential, however, to guide nursing interventions for the achievement of positive health outcomes. Development of critical thinking abilities is likely to improve accuracy of nurses' diagnoses. Newer views of critical thinking serve as a basis for critical thinking in nursing. Seven cognitive skills and ten habits of mind are identified as dimensions of critical thinking for use in the diagnostic process.
\end{abstract}

\section{KEYWORDS}

Critical Thinking.

Nursing Diagnosis.

Accuracy.

\section{RESUMEN}

La diversidad y complejidad en la interpretación de los

datos de los pacientes contribuyen al riesgo de que los diagnósticos de enfermería sean menos precisos. Pese a que los hallazgos en investigación confirmen este riesgo, debido a la enorme variación en la precisión, son esenciales diagnósticos exactos para orientar las intervenciones de enfermería en el logro de resultados positivos en la asistencia a la salud. Desarrollar habilidades para el pensamiento crítico es mejorar la precisión de esos diagnósticos. Las nuevas perspectivas del pensamiento crítico ofrecen una base para el alcance de este objetivo. Fueron identificadas siete habilidades cognitivas y diez formas de pensar como dimensiones del pensamiento crítico en el uso del proceso de diagnóstico.

\section{PALABRAS-CLAVE}

Pensamiento crítico.

Diagnóstico de enfermería.

Precisión.

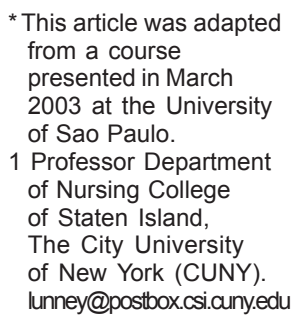

* This article was adapted from a course presented in March 2003 at the University of Sao Paulo.

1 Professor Department of Nursing College of Staten Island, The City University of New York (CUNY). lunney@postbox.csi.cuny.edu 
Classifications of nursing diagnoses are widely used in health care settings throughout the world ${ }^{(1)}$, but even widespread use of nursing diagnoses has not generated sufficient attention to diagnostic accuracy ${ }^{(2-3)}$. Accuracy should be a major goal of the diagnostic process since diagnoses are probabilistic clinical judgments and, as such, are always at risk of being inaccurate. In the near future, with implementation of electronic health records ${ }^{(4-5)}$, diagnostic accuracy will be even more important because only standard terms such as these will be used to represent diagnoses of patient data and these terms will be aggregated to produce epidemiological descriptions of patient populations. Epidemiological descriptions of human responses will be seriously flawed unless greater efforts are made to achieve accuracy of nurses' diagnoses. One of the ways that nurses can achieve higher rates of accuracy is to improve the use of critical thinking in the diagnostic reasoning process. The purpose of this two-part paper is to explain the importance of critical thinking (CT) to achieve accuracy of diagnoses, explain new views of $\mathrm{CT}$, apply $\mathrm{CT}$ in the diagnostic process with a case study, and describe ten strategies for self-development of CT abilities.

\section{CT and Diagnostic Accuracy}

Development of CT abilities for diagnostic accuracy is important because: (1) accurate interpretation of patient data is a challenging task that requires high levels of thinking abilities and intelligence; (2) the thinking abilities of nurses, like other adults, vary from high to low and can be improved; and (3) optimum use of CT abilities supports the validity of diagnoses made from data. Interpreting patient data is challenging because the signs and symptoms of nursing diagnoses overlap with one another; the responses of human beings are holistic, complex, and unique; and incorrect inferences may form the bases for nurses' diagnoses. Table 1 shows three examples of the overlap of signs and symptoms of nursing diagnoses. Such overlap can easily lead to diagnostic errors and, since diagnoses are the basis for nursing interventions, low accuracy leads to undesired patient outcomes.

Table 1 - Signs and Symptoms of Selected Nursing Diagnoses

\begin{tabular}{|c|c|}
\hline Decreased Cardiac Output & Fluid Volume Excess \\
\hline $\begin{array}{l}\text { Variations in blood pressure } \\
\text { Oliguria } \\
\text { Restlessness } \\
\text { Changes in mental status } \\
\text { Rales (crackles) } \\
\text { Dyspnea/SOB } \\
\text { Orthopnea } \\
\text { Jugular vein distention } \\
\text { Other: decreased peripheral pulses, } \\
\quad \text { cold clammy skin }\end{array}$ & $\begin{array}{l}\text { Variations in blood pressure } \\
\text { Oliguria } \\
\text { Restlessness } \\
\text { Anxiety } \\
\text { Rales (crackles) } \\
\text { Dyspnea/SOB } \\
\text { Orthopnea } \\
\text { Jugular vein distention } \\
\text { Other: + S3, + hepatojugular reflex, } \\
\quad \text { decreased hematocrit }\end{array}$ \\
\hline Anxiety & Fear \\
\hline 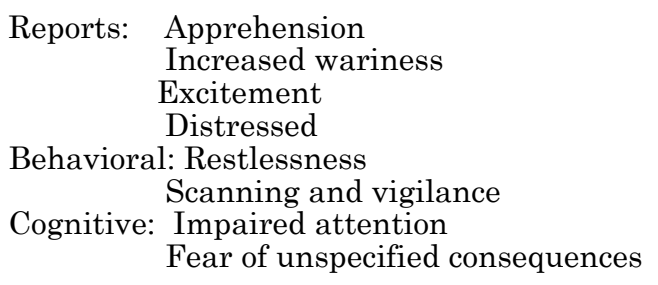 & $\begin{array}{ll}\text { Reports: } & \text { Apprehension } \\
& \text { Increased tension } \\
& \text { Excitement } \\
& \text { Feeling of dread } \\
\text { Behavioral: Avoidance or attack } & \\
\text { Increased alertness } \\
\text { Cognitive: } \begin{array}{l}\text { Identifies object of fear } \\
\text { Stimulus believed to be threat }\end{array}\end{array}$ \\
\hline Dysreflexia & Decreased Cardiac Output \\
\hline $\begin{array}{l}\text { Paroxysmal hypertension } \\
\text { Diaphoresis (above injury) } \\
\text { Pallor (below injury) } \\
\text { Chest pain } \\
\text { Bradycardia/tachycardia } \\
\text { Headache } \\
\text { Chilling } \\
\text { Conjunctival congestion } \\
\text { Paresthesia } \\
\text { Blurred vision } \\
\text { Nasal congestion }\end{array}$ & $\begin{array}{l}\text { Variation in blood pressure } \\
\text { Cold, clammy skin } \\
\text { Color changes } \\
\text { Chest pain } \\
\text { Arrhythmias } \\
\text { Fatigue } \\
\text { Jugular vein distention } \\
\text { Oliguria } \\
\text { Decreased pulses } \\
\text { Rales } \\
\text { Dyspnea } \\
\text { Restlessness }\end{array}$ \\
\hline
\end{tabular}


Table 2 shows three case study examples of harm to patients that occurred by misinterpreting the meaning of cues to these overlapping diagnoses ${ }^{(6)}$. The holistic and complex responses of human beings are influenced by many variables such as culture. Since human beings are unique, nurses cannot know the responses of persons in their care until such persons reveal who they are ${ }^{(7)}$. Accuracy, then, depends on efforts to know people through listening. Usually patients are the best sources of data and data interpretation in relation to themselves. Nurses can only know the persons in their care if they listen carefully and validate data interpretations.

Table 2 - Case Study Illustrations of the Challenge of Achieving Accuracy of Nurses Diagnoses

\section{Case Study: Mr. J}

Mr. $\mathrm{J}$ is a 68 year old man with a history of cardiac problems. He was admitted for a heart attack and congestive heart failure (CHF). The $\mathrm{CHF}$ was resolved and he was in normal sinus rhythm with a blood pressure of 120/80. His heart sounds were normal S1 and $\mathrm{S} 2$ sounds; there were no S3 sounds. He has positive jugular vein distention, negative hepatojugular reflex, a hematocrit of $36 \%$, positive pedal edema, decreased peripheral pulses, and fine crackles at his lung bases. The intravenous flow rate was 50cc per hour, his urine output was 30cc per hour, and the pulmonary wedge pressure was $20 \mathrm{~mm} \mathrm{Hg}$. The nurse decided that Mr. J. was experiencing Fluid Volume Excess and gave him a diuretic. This increased the urine output, and decreased the fluid volume and blood pressure. But the nurse's diagnosis should have been Decreased Cardiac Output. Interventions for the low accuracy diagnosis of Fluid Volume Excess contributed to exacerbating Mr. J's Decreased Cardiac Output and CHF.

\section{Case Study: Ms. S.}

Ms. S., age 55, was admitted with acutely exacerbated chronic lung disease to the critical care unit and was placed on mechanical ventilation. She was sleeping peacefully when her physician visited. Upon entering the room, he awakened her and said that he wanted to insert a Swan Ganz catheter because he suspected that recent electrocardiogram changes might be related to an impending heart attack and, since she had a history of congestive heart failure, early hemodynamic monitoring would be a benefit. The physician exited the room and asked the nurse to prepare for the Swan Ganz insertion but when the nurse entered the room, Ms. S was trying to talk and the ventilator alarms were blaring. The nurse gave Ms. S a pad and pencil and she wrote «hurt,» touched her chest, and shook her head. She kept trying to speak, causing the ventilator alarm to blare loudly.

The physician re-entered the room and said «she is very nervous, give her a Valium to calm her down.» With this, she started waving her arms widely. Both the nurse and physician had decided that Ms S was experiencing Anxiety, yet the accurate diagnosis was Fear of Swan Ganz Insertion and Negative Feelings Associated with Valium.

Case Study: Mr. H

Mr. H., age 76, was paralyzed from a T5 fracture sustained in a fall and was intubated. Two days later, the skin on his face and arms was cold, clammy and flushed, his blood pressure was 200/110, and there was no urine output. He became bradycardiac and mouthed the words "chest pain.» The nurse diagnosed Decreased Cardiac Output, ordered an electrocardiogram, decreased the flow rate of Mr. H's intravenous fluids, obtained a nitroglycerine tablet and placed it under his tongue. The nurse consulted with Mr. H's physician who thought that Mr. H was having a heart attack and ordered drugs for pain and to relax the arteries. Mr. H's blood pressure subsequently became 220/130 and he had a massive Cerebral Vascular Accident (CVA). The CVA was a complication of Dysreflexia. The nurse and physician should have diagnosed Dysreflexia, not Decreased Cardiac Output.
Critical thinking and accuracy of nurses' diagnoses. Part 1: risk of low accuracy diagnoses and new views of critical thinking 
Nurses continuously interpret patient data based on the limits of short-term memory. Humans hold $7 \pm 2$ bits of information in short term memory ${ }^{(8)}$, so data are continuously changed to inferences that summarize large amounts of data, e.g., inferences are made that people are male or female based on body type, hair style, name, type of clothing, and many other data. Inferences are the personal meanings that people derive from data (see example in Table 3). Diagnostic decisions, however, are at higher levels of abstraction and may include many inferences made from data, some of which may be incorrect.

In a systematic review of research findings on interpretations of patient data ${ }^{(3)}$, showed that nurses' interpretations, and thus accuracy, varied widely. In these studies, researchers used written or computer case simulations to measure data interpretation, which helps to maintain consistency of patient data for all subjects. It is expected that these findings probably reflect what occurs with actual clinical cases, especially since the diagnostic process is more complex with real cases. A clinical study was conducted to measure the accuracy of 62 staff nurse volunteers in three New York/New Jersey area hospitals ${ }^{(3,9)}$. This study demonstrated that accuracy of nurses' diagnoses of patients' psychosocial responses varied from high to low with 153 newly admitted patients in the three hospitals. Each nurse diagnosed one to four patients within 36 hours of admission. Two clinical experts identified the highest accuracy diagnosis for each patient in collaboration with the patients and each other. For each clinical case, the same two clinical experts independently judged the accuracy of the staff nurse's diagnosis. On a sevenpoint scale of accuracy, from -1 to +5 , only $66.2 \%$ of the diagnoses were rated as +3 level of accuracy or above, i.e., the diagnostic statements generally reflected the high relevance cues for psychosocial problems. These were nurses that were confident enough in their diagnostic ability to volunteer to be judged for accuracy. The diagnostic accuracy of nurses with low confidence in their diagnostic ability has not been studied.

The challenge of achieving accuracy of nursing diagnosis can be noted in the case study of MH, a 16 year old girl who was admitted to the hospital for diabetic ketoacidosis (see Table 4). The nurse focused on diagnosing behaviors of $\mathrm{MH}$ that contributed to this diabetic complication in order to prevent similar crises in the future. A nursing diagnosis of Ineffective Management of Therapeutic Regimen was identified and validated with $\mathrm{MH}$ but the task of identifying related factor(s) as a basis of nursing interventions was more challenging. The data revealed that $\mathrm{MH}$ had not communicated with her mother about following her diabetic diet at home, which led to poor dietary habits at home even though she followed her diet at school. The data from this case study were given to 80 experienced nurses at a conference on nursing diagnosis and the results were 46 different interpretations (Table 5) that met the criteria for seven levels of accuracy.

Table 3 - Example of inferences made from data

\section{Data Associated with an Everyday Situation:}

You are with another woman in a restaurant. A waitress is walking back and forth past your table but does not come to your table.

\section{Possible Inferences Derived from Data:}

The waitress does not respect you related to culture, gender, age, or other characteristics.

The waitress is extremely busy; has too many tables and cannot manage another one.

The waitress did not see you sitting there.

The waitress is in a personal crisis so she does not care about customer relations.

The waitress' boss told her that you were waiting for someone else.

Note: When there are multiple possible inferences from data, they cannot all be correct or accurate. 
(1) $\mathrm{MH}$ is a 16 year old female who has had type 1 diabetes for ten years. (2) She was admitted 3 days ago for treatment of an acute episode of diabetic ketoacidosis. (3) When Marian discussed with you how she managed the therapeutic regimen before hospitalization, she states that she was not adhering to her prescribed diet. (4) As Marian's nurse, you decide that Marian needs assistance to improve her management of the therapeutic regimen, especially the types of foods that she eats. (5) Marian's stay in the hospital unit is uneventful, in that medical treatments are successfully resolving the crisis.

(6) Marian's daily habits include getting up for school about 7 a.m. and rushing to get the bus by 7:30. (7) She says, she should get up about 6:30 but she likes to sleep. (8) She states that she does not want her mother to help her to get up earlier. (9) The meal she eats at school is consistent with her prescribed diet, while the two meals at home are not. (10) In the morning, she grabs whatever is quick and easy, usually toast and butter. (11) In the evening, her mother makes meals that comply with the diabetic diet but Marian states that she does not like them so she only eats part of her supper and then snacks on other foods later.

(12) Marian is able to explain to you what she should be eating and that she can adjust her diet to her lifestyle. (13)The knowledge of what foods are on her diet that she likes was not discussed with her mother because she did not want to sit down and talk with her. (14) In general, Marian and her mother argue over many of Marian's behaviors, such as school grades, smoking, and coming in late at night.

Nursing Diagnosis: Ineffective management of therapeutic regimen related to

Table 5 - Forty six diagnoses made by 80 nurses of the case study MH

\begin{tabular}{|c|c|c|c|}
\hline Diagnosis & Score* & Diagnosis & Score* \\
\hline \multicolumn{4}{|l|}{ 1. Ineffective communication } \\
\hline 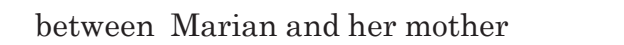 & +5 & 24.Knowledge deficit of mother & +2 \\
\hline \multicolumn{4}{|l|}{ 2. Communication gap between } \\
\hline Marian and her mother & +5 & 25.Ineffective time management & +2 \\
\hline \multicolumn{4}{|l|}{ 3. Intrafamilial communication } \\
\hline problems & +5 & 26.Developmental stage & +1 \\
\hline \multicolumn{2}{|l|}{ 4. Ineffective ability to communicate } & 27.Low self esteem & +1 \\
\hline with family & +5 & 28.Rebellious behavior & +1 \\
\hline \multicolumn{2}{|l|}{ 5. Poor communication skills \& } & 29.Self concept as different & +1 \\
\hline interaction with parent & +5 & 30.Adole: & +1 \\
\hline 6. Intrafamilial conflict & +4 & 31.Low se & +1 \\
\hline 7. Stressful mother/child develop & +4 & 32.0 & +1 \\
\hline 8. Unr & +4 & 33.La & +1 \\
\hline jith mother & +4 & 34.A & 0 \\
\hline 10.Con & +4 & 35.D & 0 \\
\hline 11.A & +4 & 36. & 0 \\
\hline 12.Adole & +3 & 37.Medical diagnos & 0 \\
\hline 13.A & +3 & 38.A & 0 \\
\hline 14.Int & +3 & 39.Kno & 0 \\
\hline 15.Ine & +3 & $40 . \mathrm{N}$ & 0 \\
\hline mother-daughter dyad & +3 & 41.Uncontrolled diabetes & 0 \\
\hline 17.Striving for autonomy and independence & +3 & 42.Immaturity as evidenced by & \\
\hline 18.Angry with mother & +2 & mother/daughter conflicts & 0 \\
\hline 19.Inability to cope: teena & +2 & 43.Hyper/hypoglycemia & 0 \\
\hline 20.Coping: Developmental stage & +2 & 44. Social isolation & 0 \\
\hline 21.Ineffective coping mechanism & +2 & 45.Arguments with her mother & 0 \\
\hline 22.Anger/rebellion/unresolved conflicts & +2 & 46.Knowledge deficit re: & \\
\hline 23.Conflict between priorities & +2 & prescribed diet & ז \\
\hline
\end{tabular}

* Scores applied using the Lunney Scoring Method (see Appendix, Lunney, 2001(9)

Critical thinking and accuracy of nurses' diagnoses. Part 1: risk of low accuracy diagnoses and new views of critical thinking 
Nurses vary in $\mathrm{CT}$ abilities, as do all adults. Even adults who achieve similar accomplishments, e.g., airline pilots, registered professional nurses with bachelor's degree preparation, vary in thinking abilities ${ }^{(10)}$. For decades, cognitive psychologists who studied many different kinds of thinking abilities verified that the thinking abilities of adults vary widely, e.g., Guilford and colleagues studied thinking abilities associated with the Guilford Structure of Intellect Model ${ }^{(10-11)}$. In Lunney's study of nurses basic thinking abilities, the range of scores on cognitive fluency was 6 to 41.5 , on cognitive flexibility was 0 to 27.5 , and on cognitive elaboration was 7 to $30.5^{(3)}$. The wide differences in these scores indicate that thinking abilities of these nurses varied from very low to high. Cognitive fluency, flexibility, and elaboration, however, are important thinking abilities to identify possible data to collect and diagnoses to consider. They are dimensions of intelligence needed to function in nursing practice. These and other thinking abilities can be improved through metacognition, i.e., thinking about thinking, increased effort, and other strategies.

Newer views of intelligence are that intelligence can continuously grow and improve ${ }^{(12-13)}$. Intelligence is "the purposive adaptation to, selection of, and shaping of environments relevant to one's life and abilities." (1988, p. 65). Intelligence develops as an interaction of the internal world, the external world, and the person's experiences of these interactions. The internal world of the individual consists of: metacomponents, knowledge acquisition components, and performance components. Metacomponents are thinking processes to plan, monitor, and evaluate problem solving. Knowledge acquisition components are thinking processes to obtain information for problem solving. Performance components are thinking processes used for problem solving. The external world of the individual consists of environments at home, work, play, and so forth. The internal world interacts with the external world through experiences. The goal of interactions and experiences are to adapt to existing environments, select new environments, or shape existing environments to new environments. For example, experiences of internal/external interactions vary from novel to routine and automatic. With increased experience, people develop ease in planning for task completion and handling complex interactions.
The experience of thinking for nursing practice situations can be further developed by thinking about thinking and making efforts to develop thinking abilities. Improved use of CT enables nurses to better evaluate the relevance of cues, recognize the relationship between cues and possible diagnoses, consider greater numbers and types of possible diagnoses, and make decisions regarding which diagnoses are best supported by the data.

\section{Newer Views of CT}

Newer views of CT are more consistent with the postmodern approach to science ${ }^{(14)}$ than older views, i.e., newer views on $\mathrm{CT}$ acknowledge the interactive nature of CT of the person and environment (e.g., Brookfield ${ }^{(15)}$, Facione ${ }^{(16)}$, Scheffer, Rubenfeld ${ }^{(17)}$ ). Older views are incorporated into newer views but, with newer views, there is less emphasis on the objective nature of thinking. Older views included abilities to (a) discriminate between good and bad arguments, (b) conduct inductive and deductive reasoning, (c) clarify assumptions, (d) weigh evidence, (e) evaluate conclusions, and (f) justify facts and values. Newer views relate these and other internal processes to external environments, thus they are broader and more inclusive of human-environment interaction. For example, Brookfield ${ }^{(15)}$ defined CT as "a productive and positive process stimulated by positive and negative events with manifestations that vary according to the context." The contextual nature of thinking and intelligence characterizes newer views.

An important research study that influenced newer views of critical thinking was Women's ways of knowing ${ }^{(18)}$. The findings of this study of 135 women from colleges and social services agencies were that the thinking processes of women develop through relationships with others. Women's perspectives on "knowing" varied according to relationships and community-based experiences. The researchers identified five phases of development in women's ways of knowing (see Summary, Table 6). This study verified that intuition is a legitimate thinking strategy for knowing. 


\section{Silence}

This most basic phase of development is characterized by an absence of voice, an experience of disconnection with others, obedience to wordless authorities, a feeling of being deaf and dumb, and it is almost impossible for the woman to describe a conception of self.

\section{Received Knowledge: Listening to Voices of Others}

This next phase of development is characterized by thinking that all knowledge originates outside the self, by looking to others and listening to others as a way of knowing, by views that words are central to knowledge, views are dualistic, and the woman does not identify with authority.

\section{Subjective Knowledge}

This next phase of development has two dimensions, the inner voice and quest for self.

The Inner Voice is characterized by a change from self as static to self as becoming (passivity to action), truth is personal, private, and subjectively known or intuited, dualistic thinking is still evident (i.e., there are right answers), the nature of authority is redefined, and orientation shifts from external to internal.

Quest for Self is characterized by seeing self in flux, a "foggy" view of self, difficulty in describing self clearly, an inward watching and listening that leads to new conceptions, open to new experiences, observing, and drawing comparisons between self and others.

\section{Procedural Knowledge: Voice of Reason}

This next phase of development is characterized by knowing that "intuitions may deceive, gut reactions can be irresponsible and no one's gut feeling is infallible, that some truths are truer than others; that they can know things never seen or touched; that truth can be shared; and that expertise can be respected (p. 93)." Two types of procedural knowing were identified: separate knowing and connected knowing.

Separate Knowing is characterized by refusal to play the conventional female role, but chose instead the lens of impersonal reason, feeling a special obligation to examine critically, to be adversarial and exclude feelings, to be strictly pragmatic, and the emphasis is on argument.

Connected Knowing is characterized by developing procedures for gaining access to other people's knowledge, learning through empathy, sharing small truths with others, refusing to judge, collaborating in connected knowing, and using personal knowledge.

\section{Constructed Knowledge: Integrating the Voices}

This last phase of development is characterized by a perspective that answers depend on the context and the frame of reference of the questioner. The woman is challenged by contradiction and conflict, attitudes include a never-ending search for truth and learning, and the woman values "real talking," i.e., sharing of ideas. The woman may still have problems with voice and express anger and frustration with lack of being "heard."

*Adapted from: Belenkey, Clinchy, Coldberger \& Tarule ${ }^{(18)}$

Many views of CT had been described by philosophers and psychologists, but, until recently no studies were done to identify the dimensions of CT that are needed for nursing practice. Scheffer and Rubenfeld ${ }^{(17)}$ conducted a Delphi study with 55 nurses who had published on the topic of critical thinking. The result was a definition of CT for nursing that includes seven cognitive skills and ten habits of mind. In Part II of this article, these seven cognitive skills will be applied to the case study of $\mathrm{MH}$.
Critical thinking and accuracy of nurses' diagnoses. Part 1: risk of low accuracy diagnoses and new views of critical thinking 
(1) International Council of Nurses. ICNP Beta 2, International Classification of Nursing Practice. Geneva; 2002.

(2) Lunney M. Where are we now? Accuracy of nurses'diagnoses: foundation of NANDA, NIC and NOC. Nurs Diagn: 1998;9:83-85.

(3) Lunney M. Critical thinking and nursing diagnosis: case studies and analyses. Philadelphia: NANDA International; 2001.

(4) Gillespie G. NCVHS to extol a standard vocab: HHS Committee completing its work culling alphabet soup of terms. available from: $<$ www.healthdatamanagement.com $>$ (may 9, 2003).

(5) Institute of Medicine. The computer-based patient record. an essential technology for health care, Revised. Washington: National Academy Press.; 1997.

(6) Lunney M, Paradiso C. Accuracy of interpreting human responses. Nurs Manage 1995;26:48H-48K.

(7) Munhall PL. 'Unknowing': toward another pattern of knowing in nursing. Nurs Outlook 1993;41:125-128.

(8) Newell A, Simon H. Human problem solving. Englewood, Prentice Hall; 1972.

(9) Lunney M, Karlik B, Kiss M, Murphy P. Accuracy of nurses' diagnoses of psychosocial responses. Nurs Diagn 1997;8:157-166.

(10) Guilford JP. Cognitive psychology with a frame of reference. San Diego: Edits; 1979.

(11) Guilford JP. Way beyond the IQ: guide to improving intelligence and creativity. Buffalo, The Creative Education Foundation; 1977.

(12) Sternberg RJ. The triarchic mind: a new theory of human intelligence. New York: Penguin; 1988.

(13) Sternberg RJ. Successful intelligence: how practical and creative intelligence determine success in life. New York: Plume Books; 1997.

(14) Rosenau PM. Post modernism and the social sciences: insights, inroads and intrusions. Princeton, Princeton University Press; 1992.

(15)Brookfield SD. Developing critical thinkers:challenging adults to explore alternative ways of thinking and acting. San Francisco: Jossey-Bass; 1991.
(16) Facione NC, Facione PA. Externalizing the critical thinking in knowledge development and clinical judgment. Nurs Outlook 1996;44:129-136.

(17) Scheffer BK, Rubenfeld MG. A consensus statement on critical thinking in nursing. J Nurs Educ 2000;39:352-359.

(18) Belenkey MF, Clinchy BM, Coldberger NR, Tarule JM. Women's ways of knowing: the development of self, voice, and mind. New York: Basic Books; 1986.

The author thanks Dra. Dina A. Lopes Monteiro da Cruz for her contributions to course development.

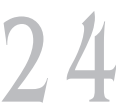

Rev Esc Enferm USP 2003; 37(2): 17-24. 